\title{
Editorial
}

\section{"O pesquisador-médico: da academia às parcerias"}

Csillag \& Schor, em artigo publicado neste número da Revista da Associação Médica Brasileira, chamam a atenção para a transformação que vem ocorrendo no perfil do pesquisador médico, basicamente em função das exigências do mercado de trabalho e, de modo especial, pelos escassos recursos destinados à pesquisa.

A pesquisa é sem dúvida fundamental para o crescimento e desenvol vimento da academia e depende do tal ento e qualidade do pesquisador e dos recursos para que el e possa desenvolver sua criatividade e dar "Iargas à sua imagi nação".

O médico-cientista é aquele médico que dedica todo ou a maior parte do seu esforço profissional na busca de novos conhecimentos sobre a saúde e as doenças, através da pesquisa (Rosenberg, L.E. - Science, 283:331, 1999), e um dos caminhos para a sua sobrevivência seria a associação com o setor privado e com investimentos na área da saúde.

A pesquisa gerada por verbas e parceria com a indústria, em particular a farmacêutica, tem características positivas. No entanto, alguns projetos que nascem desta associação geralmente obedecem protocol os estabel ecidos originariamente pela indústria, com aspectos evi dentemente comerciais ou de estratégias de vendas. Os investimentos da indústria são direcionados mais para a área da engenharia, tecnologia, nutrição e, em menor escala, para a biomédica. Muitas vezes, a pesquisa tem limites devidos a choques de interesses e conflitos éticos e de resultados.

Nenhuma instituição ou serviço sustenta sua pesquisa desta forma. A parceria pode ser importante, desde que respeitada a autonomia e criatividade do pesquisador.

A associação academia-indústria, como salientam os autores, era considerada "pouco nobre", gerando pesquisa de nível inferior, por vezes levantando suspei tas até mesmo quanto à qualidade do pesquisador. Citam exemplos de parcerias que podem mudar esta imagem abrindo um novo campo de incentivo ao pesquisador clínico.

U ma outra afirmação desta publicação é de que o pesqui sador médi co é uma espécie ameaçada de extinção. Esse fato foi motivo de um artigo especial do American J ournal of Medicine (90:271,1991), assinado por N ejad \& Marquat, com o título "Médicos Acadêmicos: dinossauros hoje?". Da mesma forma que os dinossauros, desprotegidos e incapazes de se adaptar às mudanças do meio desapareceram da superfície da terra, o pesquisador-clínico enfrenta sérias dificuldades para continuar existindo e atuando.

Os médicos acadêmicos americanos da era pós-guerra tinham na pesquisa, ensino e assistência as suas três áreas de atividades. Ao longo destes anos, cada geração manteve com sucesso essa tradição. No entanto, nesta última década a expansão da base científica da medicina e as significativas mudanças nos aspectos sociais, culturais e econômicos, têm forçado os médi cos a se reti rarem das atividades acadêmicas ou então a reduzir o tempo destinado à pesquisa.

Para a Federação da Sociedade Americana de Biologia Experimental esta preocupação é universal, pois o treinamento de médicos com interesse na pesquisa é "crítica" para o futuro da biomedicina (Brinkley, W.R. - Science, 283: 791, 1999).

U m outro fato que sugere a extinção do médico pesquisador, como comentam Csillag \& Schor, é a progressiva redução do número daqueles que buscam auxílio-pesquisa no $\mathrm{NIH}$, cujas verbas na sua maioria são destinadas à PhDs ou pesquisadores de áreas básicas, voltando o médico a exercer apenas suas atividades práticas. Várias publicações têm assinalado esta fuga e apresentado eventuais soluções para evitar esse declínio progressivo e perigoso 
para o futuro da pesquisa bi omédica (Healy, B. - New Engl. J. Med. 319: 1058, 1988; Rosenberg, L.E. - Science, 283:331,1999). Admite-se que nos Estados Unidos a carreira do médico pesquisador está declinando por uma opção natural, influenciada pela fato de que os PhDs têm muito mais possibilidade e sucesso para obter "grants".

A perspectiva do médico-cientista depende da existência de um programa de fundos para pesquisa que em nosso mei o sofre as turbulências de um mercado econômi co instável. Para mel horarmos quantitativa equal itati vamente a nossa pesquisa, os investimentos de origem governamental prescindem de uma el evação na porcentagem do PIB destinado a este fim, pois estão distantes dos recursos destinados em países desenvolvidos. O orçamento destinado à Ciência Biomédica pel o $\mathrm{NIH}$, nos Estados Unidos, é superi or ao orçamento do Ministério da Saúde do Brasil.

A parceria com a indústria permite uma maior entrada de recursos, mas é importante lembrar que nos países do primeiro mundo menos de $10 \%$ das verbas destinadas para pesquisa e desenvolvimento são provenientes de fontes não- governamentais, com exceção do Reino Unido, onde estes valores chegam a 25\% (May, R.M. - Science, 281:49, 1998).

A reduzida verba destinada à pesquisa não só dimi nui o entusiasmo e inter esse do pesquisador clínico, como afugenta o eventual jovem pesquisador, contribuindo para reduzir ainda mais a qualidade dos estudantes e do ensino nas escol as biomédicas. Tem sido enfatizada a nítida diferença entre jovens que atuam ou não na pesquisa. Os primeiros são considerados mais versáteis, imaginativos, "originais", motivados pelo aprimoramento do conhecimento científico.

A grande distância entre a qualidade da pesquisa biomédica realizada em nosso meio, com a dos países de primeiro mundo não é explicada por menor capacidade intelectual dos nossos cientistas, mas pela extraordinária diferença na capacidade dos recursos financeiros.

O sucesso na vida acadêmica, freqüentemente, está associado à habilidade do investigador em captar verbas para seus projetos. A parceria academia-indústria seguramente pode representar um estímulo significativo para os médicospesquisadores, mas deverespeitar a liberdade do investigador e a pesquisa deve ter legitimidade social, traduzida por sua aplicabilidade prática justificando o investimento.

\section{Samir Rasslan, TCBC}

Professor Titular do Departamento de Cirurgia da Faculdade de Ciências Médicas da Santa Casa de São Paulo 